\title{
The road to achieving the long-term Paris targets: energy transition and the role of direct air capture
}

\author{
Adriana Marcucci $^{1}$ (D) - Socrates Kypreos ${ }^{2} \cdot$ \\ Evangelos Panos $^{2}$
}

Received: 3 August 2016 / Accepted: 3 August 2017 / Published online: 19 August 2017

(C) Springer Science+Business Media B.V. 2017

\begin{abstract}
In this paper, we quantify the energy transition and economic consequences of the long-term targets from the Paris agreement, with a particular focus on the targets of limiting global warming by the end of the century to 2 and $1.5^{\circ} \mathrm{C}$. The study assumes early actions and quantifies the market penetration of low carbon technologies, the emission pathways and the economic costs for an efficient reduction of greenhouse gas (GHG) emissions such that the temperature limit is not exceeded. We evaluate the potential role of direct air capture (DAC) and its impact on policy costs and energy consumption. DAC is a technology that removes emissions directly from the atmosphere contributing to negative carbon emissions. We find that, with our modelling assumptions, limiting global temperature to $1.5{ }^{\circ} \mathrm{C}$ is only possible when using DAC. Our results show that the DAC technology can play an important role in realising deep decarbonisation goals and in the reduction of regional and global mitigation costs with stringent targets. DAC acts a substitute to Bio-Energy with Carbon Capture and Storage (BECCS) in the stringent scenarios. For this analysis, we use the model MERGE-ETL, a technology-rich integrated assessment model with endogenous learning.
\end{abstract}

Electronic supplementary material The online version of this article (doi:10.1007/s10584-017-2051-8) contains supplementary material, which is available to authorized users.

Adriana Marcucci

madriana@ethz.ch

Socrates Kypreos

socrates.kypreos@gmail.com

Evangelos Panos

evangelos.panos@psi.ch

1 ETH Zurich, Center of Economic Research, 8092 Zurich, Switzerland

2 Paul Scherrer Institute, Energy Economics Group, Villigen, Switzerland 


\section{Introduction}

The COP21 in Paris arrived at an agreement that foresees, amongst others, limiting global temperature increase to 2 or even $1.5^{\circ} \mathrm{C}$, the implementation and regular improvement of the intended nationally determined contributions (INDCs) and significant compensation transfers to developing countries (UNFCCC 2015). The Paris agreement is a positive step towards mitigating climate change. However, it also raises relevant questions concerning the feasibility and the costs of the proposed targets of 2 or even $1.5{ }^{\circ} \mathrm{C}$. In this paper we analyse some of these questions, in particular, the required energy transition to achieve the stringent goals and their economic costs and regional distribution. Different studies have analysed the economic impact of achieving the $2{ }^{\circ} \mathrm{C}$ under alternative policy and technology developments including delay or immediate climate action and availability of low-carbon technologies (see for instance Kriegler et al. 2013b; Riahi et al. 2015; Kriegler et al. 2015). In these analyses, when having a global agreement, global emissions peak around 2020 with a large part of the emission reductions taking place in Africa, South America, India and other emerging economies (Tavoni et al. 2015; Marcucci and Fragkos 2015). Few studies analyse scenarios consistent with the $1.5^{\circ} \mathrm{C}$ (see for instance Ranger et al. 2012; Rogelj et al. 2015). In particular, Rogelj et al. (2015) analyse the global effects on emissions, the energy sector and costs of achieving the $1.5{ }^{\circ} \mathrm{C}$. They find that energy efficiency, immediate action (from 2015) and negative emissions after 2045-2060 are key to achieve the ambitious target. Our work complements these studies by analysing regional and global consequences of limiting global temperature to 1.5 and $2{ }^{\circ} \mathrm{C}$, taking into account a growth of $\mathrm{CO}_{2}$ emissions until 2020 consistent with current developments (Friedlingstein 2014), and evaluating the potential role of removing carbon dioxide directly from the atmosphere.

Reducing carbon emissions requires the reduction of the energy demand and the use of less emitting technologies. Carbon-removal options are a potential complement to such decarbonisation strategies. Atmospheric carbon dioxide removal methods are part of the carbon removal options and include biological and chemical processes. Biological carbon removal covers a broad range of alternatives based on land use management, afforestation and bio-energy combined with carbon capture and storage (BECCS). Chemical removal of $\mathrm{CO}_{2}$ includes processes such as direct carbon dioxide capture from the ambient air (DAC) and enhanced chemical weathering (The Royal Society 2009; Schuiling and Krijgsman 2006). The role of BECCS in the future energy system (Kriegler et al. 2013a; Fuss et al. 2014; van Vuuren et al. 2013; Popp et al. 2011; Klein et al. 2014) and that of afforestation (Canadell and Raupach 2008; IPCC 2007; Obersteiner et al. 2006; Humpenoeder et al. 2014) have been largely analysed in the literature since they are arguably considered the most attractive options to realise negative carbon emissions. DAC, however, could be considered a complementary backstop technology to achieve the stringent $1.5^{\circ} \mathrm{C}$ target proposed in the Paris agreement, since it can capture the carbon produced by distributed sources such as residential heating and cooling and transportation (including aviation) (Chen and Tavoni 2013; The Royal Society 2009; Goeppert et al. 2012). In this study, we analyse the changes in the energy system, the effect on emission pathways and the cost impacts of DAC technologies in the achievement of the 1.5 and $2{ }^{\circ} \mathrm{C}$ targets.

Overall, this paper contributes to the literature with: (1) an analysis of the energy transition and mitigation costs of the long-term Paris targets, in particular, the ambitious $1.5^{\circ} \mathrm{C}$; and (2) an evaluation of the role of direct air capture and its impact on policy costs and energy consumption in achieving the 1.5 and $2{ }^{\circ} \mathrm{C}$ targets with different probabilities. The rest of the 
paper is organised as follows: in the next section, we describe the integrated assessment model used in the analysis as well as the analysed scenarios; in Sect. 3, we present the results of the different scenarios concerning energy transition, economic costs, emission pathways and the role of DAC; and finally, we discuss the main conclusions and policy implications of the analysis.

\section{Methodology}

We analyse the energy transition, economic costs and the potential role of DAC in a set of scenarios of low-emission pathways aiming at limiting global temperature increase to 1.5 and $2{ }^{\circ} \mathrm{C}$.

We use the MERGE-ETL model, ${ }^{1}$ an integrated assessment model with a top-down Ramsey-type economic model, a bottom-up representation of the energy system with endogenous technology learning and a simple climate model (Manne et al. 1995; Kypreos 2005, 2007; Marcucci 2012). In MERGE-ETL, the world is disaggregated in nine regions. Energy conversion technologies in MERGE-ETL include fossil-based, renewable and nuclear options (see Table SOM1). Carbon capture and storage is included for gas, coal and biomass in the production of both electricity and liquid fuels and the DAC technology.

The baseline in MERGE-ETL is calibrated to a middle of the road pathway consistent with the shared socioeconomic pathway 2 (SSP2) as described in Fricko et al. (2017). Potential economic development reaches a global income per capita of 65 thousand US\$2005 (PPP) per capita, annual improvements in final energy intensity of $1.4 \%$ in the period of 2015-2100 and technology learning for both fossil and renewable technologies. The availability of biomass resources is assumed to be $200 \mathrm{EJ}$ in 2050 and $300 \mathrm{EJ}$ and 2100, with a price range of 2.5-12.5 US\$/GJ. These assumptions coincide with those in the SSP2 marker, with slightly higher biomass potentials in 2100 (considered to be around 250 EJ in Fricko et al. (2017)).

We modelled a limited carbon storage potential based on Hendriks et al. (2004) with a global maximum of $1660 \mathrm{GtCO}_{2}$ (regional potentials are shown in Table SOM2). See the Supplementary Material for a more detailed description of Athe model.

\subsection{Direct air capture}

Direct air capture is a chemical process for carbon dioxide removal similar to the one used in the post-Aon Ais that in the DAC process, the $\mathrm{CO}_{2}$ is captured directly from the ambient air instead of the flue gas. The fact that the carbon is captured directly from the air poses important challenges to the development of the technology due to the low concentration, the presence of moisture and the limited temperature range (Goeppert et al. 2012). The low concentration of $\mathrm{CO}_{2}$ in the air implies, first, that large volumes of air need to be processed to capture significant amounts of carbon and, second, that the only feasible technique includes absorption or adsorption on a sorbent. The process consists of three main steps: (1) contacting the air, (2) absorption or adsorption on a liquid or solid sorbent and (3) sorbent regeneration (Lackner et al. 2012). The regeneration of the sorbent requires an amount of energy that scales up with the mass of the captured carbon and possesses important challenges regarding energy consumption (Lackner et al. 2012).

\footnotetext{
${ }^{1}$ MERGE-ETL is developed and maintained by the Energy Economics Group in the Paul Scherrer Institute.
} 
We included the DAC technology in MERGE-ETL to capture emissions from the ambient air, with costs and energy demand based on the values in the literature summarised in Table SOM3 (Baciocchi et al. 2006; Keith et al. 2006; Stolaroff 2006; Zeman 2007; Keith 2009; Lackner 2009; APS 2011; House et al. 2011; Simon et al. 2011). Future cost estimates and energy requirements for the DAC technology are very uncertain, with estimations that go from $\$ 30$ up to $\$ 1000$ per $\mathrm{tCO}_{2}$. We assume that the DAC technology is available from 2060 (following Chen and Tavoni 2013) with an initial cost of $600 \mathrm{US}_{2010} / \mathrm{tCO}_{2}$ captured and a floor cost of $200 \mathrm{US} \$_{2010} / \mathrm{tCO}_{2}$, covering the ranges in the literature (see Table SOM3). Regarding the thermal energy use, the theoretical minimum is estimated to be around $1 \mathrm{GJ} /$ $\mathrm{tCO}_{2}$ (APS 2011; Keith et al. 2006); actual energy use estimations are in the range of 3-10 GJ/ $\mathrm{tCO}_{2}$. We model an increase in the efficiency, with an initial thermal energy requirement of 8.1 GJ/tCO 2 (APS 2011; Chen and Tavoni 2013) and a minimum value of $5 \mathrm{GJ} / \mathrm{tCO}_{2}(\mathrm{Zeman}$ 2007). Moreover, following APS (2011), Baciocchi et al. (2006) and Stolaroff (2006), we consider an electricity consumption of $1.8 \mathrm{GJ} / \mathrm{tCO}_{2}$ captured.

\subsection{Analysed scenarios}

We analyse scenarios that model the long-term temperature targets of the Paris agreement and a counterfactual BAU scenario without any climate or technology policy. The climate scenarios represent global immediate mitigation cases aiming at reducing greenhouse gases (GHGs) to limit global warming to less than 2 and $1.5{ }^{\circ} \mathrm{C}$ with different probabilities. Cumulative carbon emissions are considered a good representation of global temperature increase given their near-linear relationship (Friedlingstein et al. 2014). However, there are large uncertainties concerning the response of the climate system and the contributions of other GHGs; hence, the scenarios are usually expressed as probabilities of not exceeding the temperature targets. The bar plot in Fig. 1 presents the probabilities of staying below 1.5 and $2{ }^{\circ} \mathrm{C}$ in three scenario categories with increasing stringency (based on Fig. 6.14b from the WP3 of IPCC 5AR (IPCC 2014)). The analysed scenarios in this paper correspond to the upper-end probability of each scenario category that we label using a representative temperature target (red markers in Fig. 1). For instance, the most stringent scenario named $1.5_{50}$ has a $50 \%$ probability of remaining below $1.5{ }^{\circ} \mathrm{C}$, which corresponds to 85 and $97 \%$ probabilities of remaining below 2 and $2.5^{\circ} \mathrm{C}$, respectively (IPCC 2014).

The target in these scenarios is modelled as remaining carbon emissions $\left(\mathrm{CO}_{2}\right.$ budgets) after 2020 (see Fig. 1). The $\mathrm{CO}_{2}$ budgets for the $2{ }^{\circ} \mathrm{C}$ scenarios are based on Friedlingstein et al. (2014). The $\mathrm{CO}_{2}$ budget of the $1.5^{\circ} \mathrm{C}$ with $50 \%$ probability corresponds to the median of the 2011-2100 global carbon budgets presented in Rogelj et al. (2015), which is $350 \mathrm{GtCO}_{2}$, adjusted to 2020-2100 to account for increasing $\mathrm{CO}_{2}$ emissions until 2020, following Friedlingstein et al. (2014). To estimate the GHG budgets, we imposed first the $\mathrm{CO}_{2}$ budgets, and then, we determined the resulting shadow price of carbon and used it as a tax for the other GHGs to estimate the budget for all GHGs.

\section{The road to achieving the long-term Paris targets and the role of DAC}

The climate targets have effects on the development of the energy system and different regional mitigation costs. The DAC technology contributes to the achievement of the 


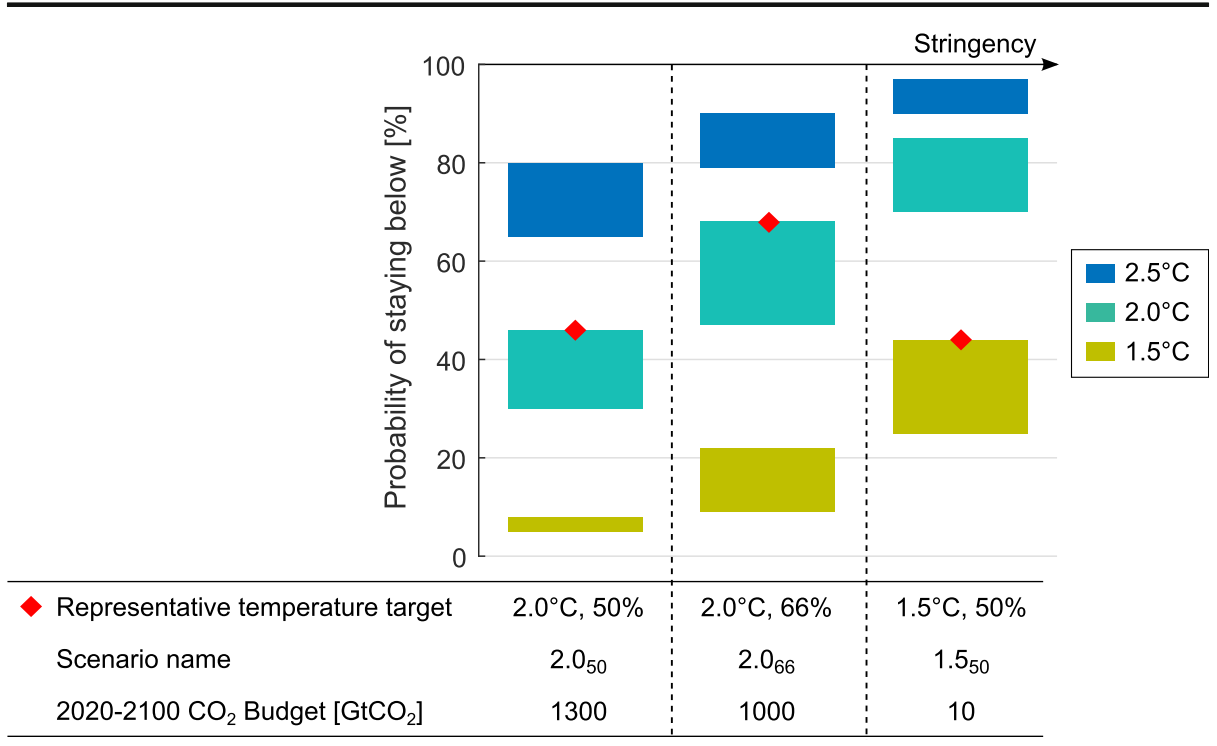

Fig. 1 Analysed scenarios: $\mathrm{CO}_{2}$ budgets and probabilities of staying below the temperate targets

mitigation goals, particularly in the $1.5_{50}$ scenario, whose stringent target otherwise results in an infeasible problem for the MERGE-ETL model. ${ }^{2}$

\subsection{Energy transition}

Table 1 presents the electricity and non-electric final energy consumption for the different temperature targets (including energy used by DAC). In the counterfactual BAU scenario, the final energy consumption reaches 872 and 940 EJ by 2050 and 2100, respectively. Total energy consumption has a similar reduction compared to BAU in the scenarios with and without DAC: $22-28 \%$ in 2050 and 2100 . The main difference when using the DAC technology is that a part of the final energy is used by DAC to capture emissions directly from the air, implying a slightly lower energy use by the consumers. All scenarios result in an electrification of the energy system, in particular, the $1.5_{50}$ case, where electricity demand is higher than in the BAU.

In the BAU scenario, primary energy is mainly provided by fossil fuels with a share of $85 \%$ in 2050 and $62 \%$ in 2100 when they are partially replaced by renewable energy forms. The climate policies lead to a significant reduction in the use of fossil fuels in the energy production. In the electricity sector, coal is replaced with nuclear and renewable-based technologies (see Fig. 2a). The non-electric energy production shifts from oil, gas and synthetic liquids (from coal and biomass) to biofuels with CCS, synthetic liquids from coal with CCS and hydrogen, mainly from solar thermal processes (see Fig. 2b).

The use of the DAC technology has some consequences on the technology deployment driven mainly by the increase in the heat demand due to the large use of direct air capture. Figure 2 shows the final energy production for the two most stringent scenarios when DAC is available. The heat needed by DAC is produced from hydrogen and fossil fuels. BECCS is an

\footnotetext{
${ }^{2}$ Note that an infeasible optimization problem does not necessarily imply an infeasible target in the real world. It refers to the fact that with the current modelling assumptions, the problem cannot be solved.
} 
Table 1 Final electricity and non-electric energy consumption

\begin{tabular}{|c|c|c|c|c|c|c|c|c|}
\hline & \multicolumn{4}{|c|}{ Electricity (EJ) } & \multicolumn{4}{|c|}{ Non-electric energy (EJ) } \\
\hline & \multicolumn{2}{|l|}{2050} & \multicolumn{2}{|l|}{2100} & \multicolumn{2}{|l|}{2050} & \multicolumn{2}{|l|}{2100} \\
\hline & $\begin{array}{l}\text { Without } \\
\text { DAC }\end{array}$ & DAC & $\begin{array}{l}\text { Without } \\
\text { DAC }\end{array}$ & DAC & $\begin{array}{l}\text { Without } \\
\text { DAC }\end{array}$ & DAC & $\begin{array}{l}\text { Without } \\
\text { DAC }\end{array}$ & DAC \\
\hline BAU & 298.7 & & 416.3 & & 573.1 & & 524.0 & \\
\hline $2.0_{50}$ & 272.9 & 268.4 & 423.7 & $419.2+(20.5)$ & 396.2 & 413.3 & 291.5 & $291.5+(62.2)$ \\
\hline $2.0_{66}$ & 283.4 & 273.6 & 444.1 & $392.9+(38.5)$ & 344.4 & 381.9 & 257.7 & $273.2+(116.7)$ \\
\hline $1.5_{50}$ & Infes & 342.2 & Infes & $522.2+(68.9)$ & Infes & 201.4 & Infes & $146.7+(209.8)$ \\
\hline
\end{tabular}

The values in parentheses indicate the energy used by the DAC technology

important technology in both the electricity sector and the non-electric energy production. However, its use is limited given the assumptions on biomass availability.

Figure 3 presents the changes in cumulative energy production from the different technologies induced by the deployment of DAC. The use of fossil fuels, in particular, the NGCC technology in power generation and oil and gas for non-electric energy uses, increases in the first half of the century given the additional carbon removal capacity provided by DAC from 2060. After 2060, the heat required by the DAC technology is supplied by hydrogen from solar thermal processes and biomass, hence the increase in the cumulative production of nonelectric energy from renewables. Moreover, biomass is shifted from the electricity sector to the non-electric energy production resulting in a decrease of the electricity produced from renewables and an increase in gas (CCS) as a replacement.

\subsection{Carbon emissions and the effect of DAC}

In the BAU scenario, total carbon emissions reach a level of $70.1 \mathrm{GtCO}_{2}$ in 2100 and a global temperature increase of $4.5^{\circ} \mathrm{C}$ by 2100 . When implementing the carbon policies, the decrease in the energy demand and the shift in the energy system towards renewables and CCS results in a considerable decrease in $\mathrm{CO}_{2}$ emissions (see Fig. 4a) with a peak in emissions in 2020 or 2030. Achieving the $1.5_{50}$ target requires significantly lower emissions, especially until 2060 ,

(a) Electricity production

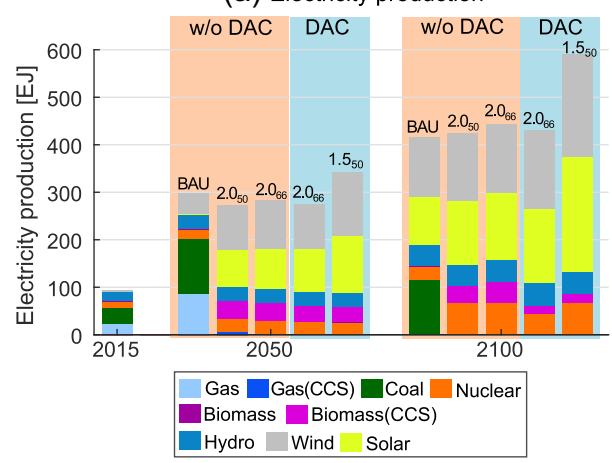

(b) Non-electric energy production

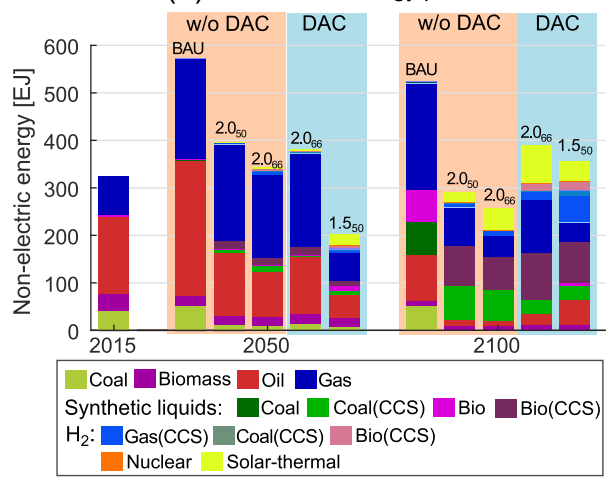

Fig. 2 Energy production in the different climate scenarios without and with DAC 


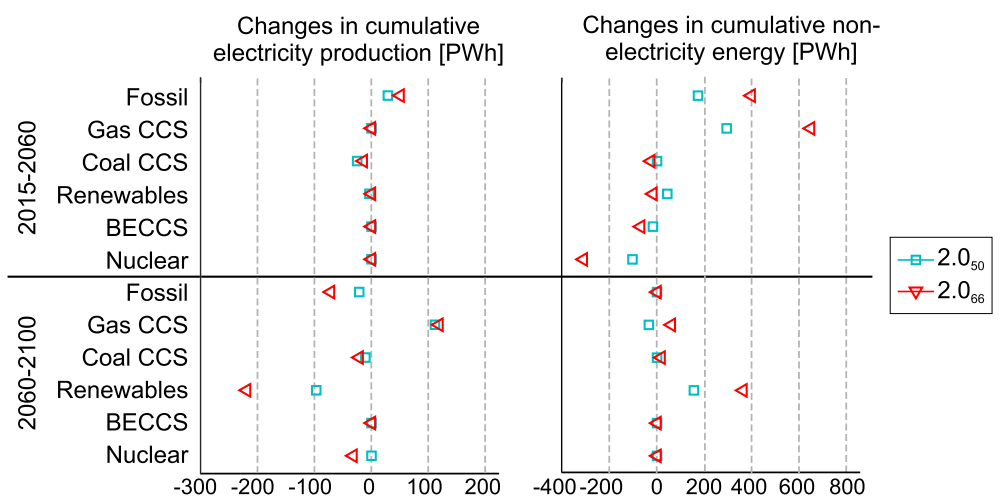

Fig. 3 Changes in cumulative energy production: DAC - no DAC. A negative value represents a decrease in the use of the technology

with a reduction in 2050 compared to the BAU scenario of $91 \%$ and negative emissions afterwards. All scenarios result in net negative emissions by the end of the century reaching -7.9 and $-10.6 \mathrm{GtCO}_{2}$ for the scenarios without DAC. The availability of the DAC technology allows for a larger increase in short-term emissions until the middle of the century and stronger reductions in the long term (see dotted lines in Fig. 4a), resulting in emissions by 2100 of $-15.9,-25.6$ and $-42.8 \mathrm{GtCO}_{2}$. The perfect foresight model finds cost optimal to increase emissions before the year when DAC starts to be available and to have negative emissions towards the end of the modelling horizon (learning effect for DAC). Hence, the flexibility to have negative emissions at the end of horizon using DAC leaves room for lowering the $\mathrm{CO}_{2}$ prices (and allowing higher $\mathrm{CO}_{2}$ emissions) in the mid-term period. As a result, this flexibility

(a) Total $\mathrm{CO}_{2}$ emissions, dotted lines

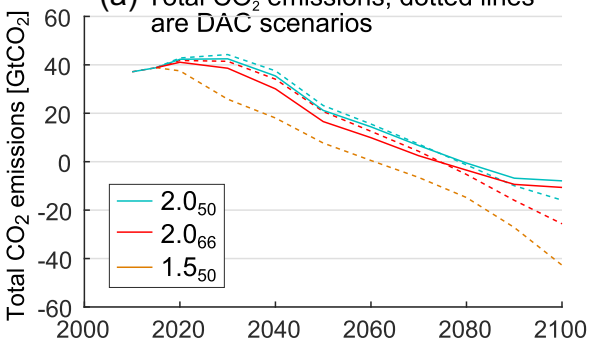

(b) Global temperature increase

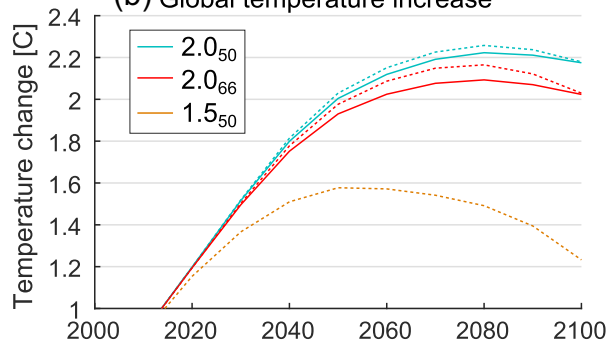

(d) Regional $\mathrm{CO}_{2}$ abatement with DAC
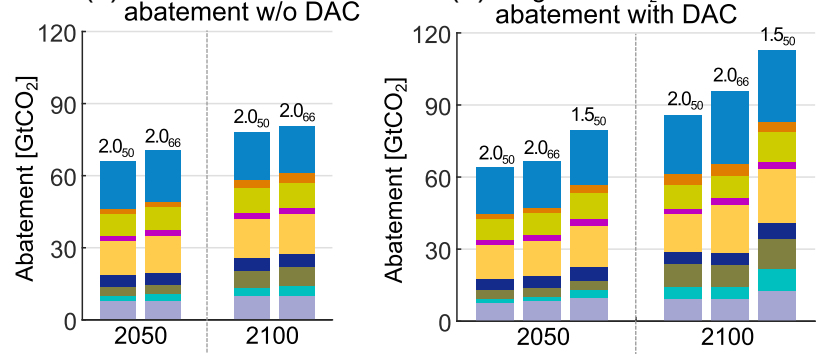

Fig. 4 Global $\mathrm{CO}_{2}$ emissions, global mean temperature increase calculated using the MAGICC 6 model (Meinshausen et al. 2011) and regional abatement with DAC and without DAC (compared to BAU) 
causes a temperature overshoot before reaching the target (see Fig. 4b), particularly larger in the $1.5_{50}$ case.

The emissions from the electricity sector become negative in all scenarios with or without DAC from 2050, whilst the emissions from non-electric energy uses continue to be positive until 2080 due to the use of fossil fuels. Abatement options in non-energy sectors in MERGEETL are modelled with an exogenous abatement curve; therefore, the options to reduce these emissions are limited resulting in similar abatement in all the analysed scenarios.

Figure $4 \mathrm{c}, \mathrm{d}$ present the regional $\mathrm{CO}_{2}$ abatement relative to the BAU for the different scenarios without and with DAC, respectively. Most of the abatement takes place in the developing regions (especially China and the ROW) that account for around $70 \%$ of the emission reductions in 2100 in the scenarios without DAC and $75 \%$ in the cases with DAC. The reduction of $\mathrm{CO}_{2}$ emissions in Russia and the Middle East has a significant increase when considering direct air capture given their large carbon storage potentials.

Figure 5 shows the regional distribution of the $\mathrm{CO}_{2}$ emissions captured with DAC and the changes in stored carbon from fossil fuels and BECCS between the scenarios with and without DAC. The contribution of the DAC technology is limited by the $\mathrm{CO}_{2}$ storage capacity of the different regions; thus, countries with large storage capacity, i.e. Middle East, Russia and Canada, contribute to the largest negative emissions at the end of the century. As expected, the contribution of the DAC technology increases with the stringency of the climate policy, with 11.4, 21.4 and $38.3 \mathrm{GtCO}_{2}$ captured in 2100 in the three scenarios.

DAC plays an important role in achieving the climate targets, in particular, with the increase in stringency. DAC accounts for 23,33 and $38 \%$ of the total carbon captured in 2100 in the $2_{50}, 2_{66}$ and $1.5_{50}$ cases, respectively. Compared to the scenarios without DAC, DAC partially substitutes the CCS from energy sources due to the limits in storage and competitive capture prices. The substitution is intertemporal; in the first half of the century, the perfect foresight of the model allows for a decrease in the deployment of BECCS and coal with CCS and an increase in gas (see Fig. 3), resulting in lower quantities of captured carbon from energy sources. This is later compensated by additional $\mathrm{CO}_{2}$ captured in the second half of the century using DAC.

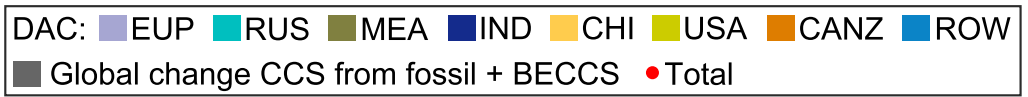
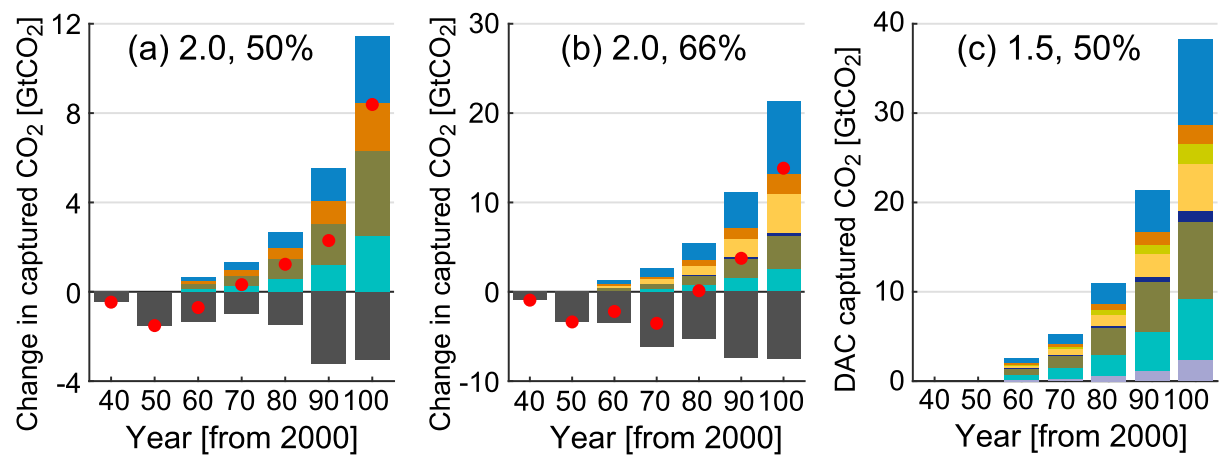

Fig. 5 Regional distribution of $\mathrm{CO}_{2}$ emissions captured with $\mathrm{DAC}$ and changes in captured $\mathrm{CO}_{2}$ emissions with and without DAC (DAC - no DAC). Note that Fig. $5 \mathrm{c}$ does not include the changes compared to the case without DAC for the $1.5_{50}$ scenario that is not feasible for the assumptions and current calibration of the MERGE-ETL model 


\subsection{Regional costs to achieve the long-term Paris targets}

The global cumulative 2020-2100 economic output losses ${ }^{3}$ to achieve the $2{ }^{\circ} \mathrm{C}$ target without the DAC technology are 2.3 and 3\% (see Fig. 6). Developing regions and regions that export fossil fuels have relatively larger costs, in particular, with the increase in the stringency of the climate target. For instance, in the $2.0_{66}$ scenario without DAC, cumulative losses in Russia, India and China are 10, 3.2 and 4\%, respectively, compared to 2.8 and $2 \%$ in EU and the USA. Russia is affected mainly as an exporter of fossil fuels that is confronted with a situation of low demand for fuels and falling prices. China and India, on the other hand, are the economies with the larger economic growth in the BAU scenario, driven mainly by energy from fossil fuels; consequently, the climate change mitigation policies have a larger impact on their economic development. The blue shaded bars in Fig. 6 present the global and regional economic output losses when the DAC technology is deployed. The additional flexibility in emission reductions provided by the availability of the DAC technology reduces the mitigation costs of achieving the climate targets to $2 \%$ and $2.5 \%$ for the $2_{50}$ and $2_{66}$ cases, respectively. This is consistent with the changes in the marginal price of carbon, that in 2100 are reduced by 35 and $19 \%$, for the 66 and $50 \%$ probabilities of staying below $2^{\circ} \mathrm{C}$ (see Figure SOM1b).The DAC technology does not have a large impact on the regional distribution of the mitigation costs and Russia, India and China continue to be the regions with the largest losses. The economic losses in the $1.5_{50}$ scenario are significantly larger than in the other cases with a global value of $7.3 \%$. This is reflected in the high price of carbon of $\$ 4200$ per ton of $\mathrm{CO}_{2}$ in 2100 (see Figure SOM1b). The Middle East is the region with the lowest increase in economic costs compared to the $2{ }^{\circ} \mathrm{C}$ target due to its large capacity of carbon storage.

\section{Discussion and conclusions}

The agreement in the COP21 in Paris aims at limiting global temperature to 2 and even $1.5^{\circ} \mathrm{C}$. In this paper, we analysed these Paris targets by imposing a constraint on remaining carbon emissions such that the global temperature increase is limited to $2{ }^{\circ} \mathrm{C}$ with different probabilities and $1.5^{\circ} \mathrm{C}$. We find that achieving these targets has important consequences in the energy system and the economy as a whole. Changes in the energy system include a significant reduction in final energy demand and a complete shift to renewables, nuclear and BECCS for electricity and hydrogen production. The global economic losses in the different efficient scenarios increase in a non-linear way with the increase in the stringency of the target. Moreover, in our analysis, achieving the Paris targets has higher economic impact in the developing regions due to their fossil-based energy system in the BAU case, a consequence of higher economic growth.

We find that complementary policies and immediate action, in particular, for the $1.5{ }^{\circ} \mathrm{C}$ case, are needed to attain the Paris targets. Such policies may include promotion of renewables, changes in consumer behaviour to reduce energy consumption and support to research and development of other decarbonisation or carbon removal technologies, such as BECCS, direct air capture or geoengineering. DAC, in particular, could contribute to mitigating the emissions produced by distributed sources, such as heating, cooling and transportation. In particular,

\footnotetext{
${ }^{3}$ Cumulative economic output losses are calculated using a 5\% discount rate.
} 


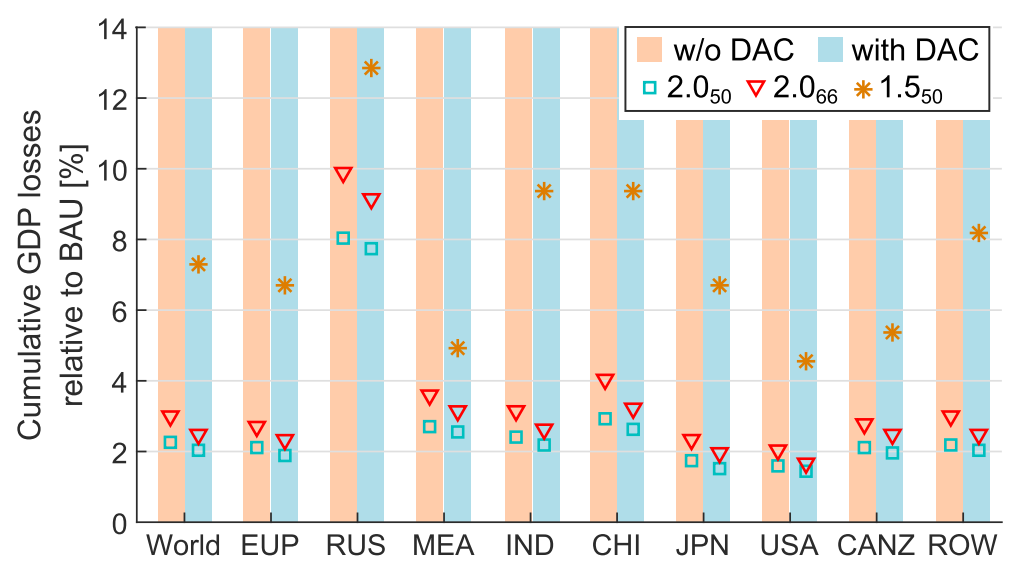

Fig. 6 Cumulative discounted 2020-2100 economic output losses without and with DAC

in energy-exporting countries, such as Russia and the Middle East, which have the largest $\mathrm{CO}_{2}$ storage capacities.

We evaluate the feasibility of the $1.5{ }^{\circ} \mathrm{C}$ target and the impacts on the economy and the energy system. In our model, attaining this Paris target depends on the immediate reduction of $\mathrm{CO}_{2}$ emissions and negative emissions after 2060, which require the use of additional mitigation technologies such as BECCS and direct air capture. A deep decarbonisation of the energy system and a strong reduction of final energy demands without complementary $\mathrm{CO}_{2}$ removal are not enough to realise this Paris target. This does not imply that limiting global temperature increase to $1.5{ }^{\circ} \mathrm{C}$ is infeasible, but it does reflect the non-linear increase of mitigation costs when the targets become more stringent due to the need of expensive mitigation options. Alternative technologies, not analysed in this paper and not modelled in our framework, are mitigation options in the industrial sector and other carbon removal technologies or geoengineering.

We analyse the potential role of the direct air capture technology to remove carbon dioxide from the ambient air as a complement to renewable-based technologies and CCS from fossil fuel and biomass. We find that this technology can contribute to the achievement of the mitigation goals and it is used as a complement to renewables and BECCS. With an increase in the climate mitigation target, DAC plays an increasing role reducing $\mathrm{CO}_{2}$. In the $2_{66}$ and the 1.5 cases, the DAC technology captures 21 and $40 \mathrm{GtCO}_{2}$ in 2100 , respectively. We also find that DAC can contribute to reducing the carbon tax and economic impacts of the decarbonisation. In the $2_{66}$ scenario, the carbon tax is about $35 \%$ lower compared to the case without DAC. However, $40 \mathrm{GtCO}_{2}$ is more than the current global emissions, which implies that developing DAC to such a scale would require major efforts in the construction of the infrastructure and the buildup of a large $\mathrm{CO}_{2}$ industry with the adequate regulation. Hence, the results concerning the reduction in mitigation costs could be influenced by other factors not included in this analysis, such as building the network for $\mathrm{CO}_{2}$ transport or safety and regulation measures. One important limit in the development of DAC is storage capacity. For this reason, countries with large storage capacity benefit the most from the availability of such technology.

Actual temperature change in the scenarios with DAC has an overshoot before reaching the target at the end of the century, particularly large in the $1.5^{\circ} \mathrm{C}$ target scenario. The consequences of such overshoots (on sea level rise, for instance) need to be taken into account to fully assess the role of DAC. However, the temperature increase in 2100 in the $1.5_{50}$ case is 
$1.23{ }^{\circ} \mathrm{C}$, lower than the long-term target (the $25-75 \%$ range in the MAGICC simulations is $\left.1.12-1.47^{\circ} \mathrm{C}\right)$.

Notwithstanding the insights gained in the present analysis regarding the role of direct air capture in meeting the climate change mitigation targets and reducing its cost, the uncertainty regarding the cost and performance of the technology shall not be neglected. This implies that additional analysis is necessary, perhaps by employing stochastic modelling, since the technical change and R\&D infusions can accelerate its penetration (or viewed another way if the assumed learning rates are not met then its role can be reduced significantly). In addition, the modelling framework of MERGE-ETL also has some limitations. These include amongst others rough aggregation of very heterogeneous countries in the rest of the world region and a simplified representation of the intermittency of electricity supply from wind and solar energy. These limitations can overestimate the potential of different countries and renewable technologies to contribute to climate change mitigation and affect the estimated capital transfers and GDP losses.

Acknowledgements S. Kypreos thanks ETSAP for supporting his participation to the IEW-2015. A. Marcucci and E. Panos thank the financial support of Swiss Competence Center for Energy Research (SCCER) CREST and SCCER - Supply of Electricity, which are in turn financially supported by the Swiss Commission for Technology and Innovation (CTI). We would also like to thank the three anonymous reviewers for their valuable suggestions and comments.

\section{References}

APS (2011). Direct air capture of $\mathrm{CO}_{2}$ with chemicals: a technology assessment for the APS panel on public affairs. Technical Report American Physical Society

Baciocchi R, Storti G, Mazzotti M (2006) Process design and energy requirements for the capture of carbon dioxide from air. Chem Eng Process Process Intensif 45:1047-1058

Canadell JG, Raupach MR (2008) Managing forests for climate change mitigation. Science 320:1456-1457

Cen C, Tavoni M (2013) Direct air capture of $\mathrm{CO}_{2}$ and climate stabilization: a model based assessment. Clim Chang 118:59-72

Fricko O, Havlik P, Rogelj J, Klimont Z, Gusti M, Johnson N, Kolp P, Strubegger M, Valin H, Amann M, Ermolieva T, Forsell N, Herrero M, Heyes C, Kindermann G, Krey V, McCollum DL, Obersteiner M, Pachauri S, Rao S, Schmid E, Schoepp W, Riahi K (2017) The marker quantification of the shared socioeconomic pathway 2: a middle-of-the-road scenario for the 21st century. Glob Environ Chang 42: 251-267

Friedlingstein P, Andrew RM, Rogelj J, Peters GP, Canadell JG, Knutti R, Luderer G, Raupach MR, Schaeffer M, van Vuuren DP, Le Quere C (2014) Persistent growth of $\mathrm{CO}_{2}$ emissions and implications for reaching climate targets. Nat Geosci 7:709-715

Fuss S, Canadell JG, Peters GP, Tavoni M, Andrew RM, Ciais P, Jackson RB, Jones CD, Kraxner F, Nakicenovic N, Le Quere C, Raupach MR, Sharifi A, Smith P, Yamagata Y (2014) Betting on negative emissions. Nat Clim Chang 4:850-853

Goeppert A, Czaun M, Surya Prakash GK, Olah GA (2012) Air as the renewable carbon source of the future: an overview of $\mathrm{CO}_{2}$ capture from the atmosphere. Energy Environ Sci 5:7833-7853

Hendriks, C., Graus, W., \& van Bergen, F. (2004). Global carbon dioxide storage potential and costs. Technical Report Ecofys

House KZ, Baclig AC, Ranjan M, van Nierop EA, Wilcox J, Herzog HJ (2011) Economic and energetic analysis of capturing $\mathrm{CO}_{2}$ from ambient air. Proc Natl Acad Sci 108:20428-20433

Humpenoeder F, Popp A, Dietrich JP, Klein D, Lotze-Campen H, Bonsch M, Bodirsky BL, Weindl I, Stevanovic M, Mueller C (2014) Investigating afforestation and bioenergy CCS as climate change mitigation strategies. Environ Res Lett 9:064029

IPCC (2007) Climate Change 2007. Forestry, Contribution of Working Group III to the Fourth Assessment Report of the Intergovernmental Panel on Climate Change. IPCC 
IPCC (2014). Clarke L., K. Jiang, K. Akimoto, M. Babiker, G. Blanford, K. Fisher-Vanden, J.-C. Hourcade, V. Krey, E. Kriegler, A. Löschel, D. McCollum, S. Paltsev, S. Rose, P.R. Shukla, M. Tavoni, B.C.C. van der Zwaan, and D.P. van Vuuren, 2014: Assessing transformation pathways. In: Climate Change 2014: Mitigation of Climate Change. Contribution of Working Group III to the Fifth Assessment Report of the Intergovernmental Panel on Climate Change. Cambridge University Press, Cambridge, United Kingdom and New York, NY, USA

Keith DW (2009) Why capture $\mathrm{CO}_{2}$ from the atmosphere? Science 325:1654-1655

Keith D, Ha-Duong M, Stolaroff J (2006) Climate strategy with $\mathrm{CO}_{2}$ capture from the air. Clim Chang 74:17-45

Klein D, Luderer G, Kriegler E, Strefler J, Bauer N, Leimbach M, Popp A, Dietrich J, Humpener F, LotzeCampen H, Edenhofer O (2014) The value of bioenergy in low stabilization scenarios: an assessment using remind-magpie. Clim Chang 123:705-718

Kriegler E, Edenhofer O, Reuster L, Luderer G, Klein D (2013a) Is atmospheric carbon dioxide removal a game changer for climate change mitigation? Clim Chang 118:45-57

Kriegler E, Tavoni M, Aboumahboub T, Luderer G, Calvin K, Demaere G, Krey V, Riahi K, Rosler H, Schaeffer M, Van Vuuren DP (2013b) What does the 2C target imply for a global climate agreement in 2020? The LIMITS study on Durban platform scenarios. Climate Change Economics $04: 1340008$

Kriegler E, Riahi K, Bauer N, Schwanitz J, Petermann N, Bosetti V, Marcucci A, Otto S, Paroussos L, Rao S, ArroyoCurras T, Ashina S, Bollen J, Eom J, Hamdi-Cherif M, Longden T, Kitous A, Mejean A, Sano F, Schaeffer M, Wada K, Capros P, van Vuuren D, Edenhofer O (2015) Making or breaking climate targets: the AMPERE study on staged accession scenarios for climate policy. Technol Forecast Soc Chang 9(Part A):24 44

Kypreos S (2005) Modeling experience curves in MERGE (model for evaluating regional and global effects). Energy 30:2721-2737

Kypreos S (2007) A MERGE model with endogenous technological change and the cost of carbon stabilization. Energy Policy 35:5327-5336

Lackner KS (2009) Capture of carbon dioxide from ambient air. Eur. Phys. J. Special Topics 176:93-106

Lackner KS, Brennan S, Matter JM, Park A-HA, Wright A, van der Zwaan B (2012) The urgency of the development of $\mathrm{CO}_{2}$ capture from ambient air. Proc Natl Acad Sci 109:13156-13162

Manne A, Mendelsohn R, Richels R (1995) MERGE: a model for evaluating regional and global effects of GHG reduction policies. Energy Policy 23:17-34

Marcucci, A (2012) Realizing a sustainable energy system in Switzerland in a global context. Ph.D. thesis ETH Zurich

Marcucci A, Fragkos P (2015) Drivers of regional decarbonization through 2100: a multi-model decomposition analysis. Energy Econ 51:111-124

Meinshausen M, Raper SCB, Wigley TML (2011) Emulating coupled atmosphere-ocean and carbon cycle models with a simpler model, MAGICC6: part I-model description and calibration. Atmos Chem Phys 11:1417-1456

Obersteiner M, Alexandrov G, Benitez P, McCallum I, Kraxner F, Riahi K, Rokityanskiy D, Yamagata Y (2006) Global supply of biomass for energy and carbon sequestration from afforestation/reforestation activities. Mitig Adapt Strateg Glob Chang 11:1003-1021

Popp A, Dietrich JP, Lotze-Campen H, Klein D, Bauer N, Krause M, Beringer T, Gerten D, Edenhofer O (2011) The economic potential of bioenergy for climate change mitigation with special attention given to implications for the land system. Environ Res Lett 6:034017

Ranger $\mathrm{N}$ et al (2012) Is it possible to limit global warming to no more than $1.5{ }^{\circ} \mathrm{C}$ ? Clim Chang 111:973-981

Riahi K, Kriegler E, Johnson N, Bertram C, den Elzen M, Eom J, Schaeffer M, Edmonds J, Isaac M, Krey V, Longden T, Luderer G, M'ejean A, McCollum DL, Mima S, Turton H, van Vuuren DP, Wada K, Bosetti V, Capros P, Criqui P, Hamdi-Cherif M, Kainuma M, Edenhofer O (2015) Locked into Copenhagen pledgesimplications of short-term emission targets for the cost and feasibility of long-term climate goals. Technol Forecast Soc Chang 9(Part A):8-23

Rogelj J, Luderer G, Pietzcker RC, Kriegler E, Schaeffer M, Krey V, Riahi K (2015) Energy system transformations for limiting end-of-century warming to below $1.5^{\circ} \mathrm{C}$. Nature Clim. Change 5:519-527

Schuiling RD, Krijgsman P (2006) Enhanced weathering: an effective and cheap tool to sequester $\mathrm{CO}_{2}$. Clim Chang 74:349-354

Simon A, Kaahaaina NB, Friedmann SJ, Aines RD (2011) Systems analysis and cost estimates for large scale capture of carbon dioxide from air. Energy Procedia 4:2893-2900 10th International Conference on Greenhouse Gas Control Technologies

Stolaroff, J. K. (2006) Capturing $\mathrm{CO}_{2}$ from ambient air: a feasibility assessment. Ph.D. thesis Carnegie Mellon University 
Tavoni M, Kriegler E, Riahi K, van Vuuren DP, Aboumahboub T, Bowen A, Calvin K, Campiglio E, Kober T, Jewell J, Luderer G, Marangoni G, McCollum D, van Sluisveld M, Zimmer A, van der Zwaan B (2015) Post-2020 climate agreements in the major economies assessed in the light of global models. Nat Clim Chang 5:119-126

The Royal Society (2009) Geoengineering the climate. Science, governance and uncertainty

UNFCCC (2015) Adoption of the Paris agreement. Proposal by the President. Technical Report UN Framework Convention on Climate Change

van Vuuren D, Deetman S, van Vliet J, van den Berg M, van Ruijven B, Koelbl B (2013) The role of negative $\mathrm{CO}_{2}$ emissions for reaching $2{ }^{\circ} \mathrm{C}$-insights from integrated assessment modelling. Clim Chang 118:15-27 Zeman F (2007) Energy and material balance of $\mathrm{CO}_{2}$ capture from ambient air. Environ Sci Technol 41:75587563 